\title{
Is Obesity Associated with an Increased Risk for Airway Hyperresponsiveness and Development of Asthma?
}

Sat Sharma, MD, FRCPC, Adarsh Tailor, MD, FRCPC, Richard Warrington, MD, PhD, FRCPC, and Mary Cheang, M. Math

\begin{abstract}
We investigated the association between airway hyperresponsiveness (AHR) and obesity in adults referred for confirmation of asthma diagnosis. Data were analyzed for obesity class I (body mass index [BMI] $\left.30-34.9 \mathrm{~kg} / \mathrm{m}^{2}\right)$, class II (BMI $\left.\geq 35-39.9 \mathrm{~kg} / \mathrm{m}^{2}\right)$, and class III (BMI $\geq 40 \mathrm{~kg} / \mathrm{m}^{2}$ ). Of 861 subjects, 401 demonstrated AHR; the mean dose of methacholine was $4.16 \pm 2.55 \mathrm{mg} / \mathrm{mL}$. A significant association between obesity and AHR was evident for all subjects: the odds ratio was 1.37 (95\% $\mathrm{Cl} 1.02-1.82 ; p=.0317)$. One unit of increased BMI $\left(1 \mathrm{~kg} / \mathrm{m}^{2}\right)$ was associated with a $3.1 \%$ increase in AHR risk $(95 \% \mathrm{Cl} 1.01-1.05, p<.005)$. The odds ratio increased from $1.86(95 \% \mathrm{Cl} 1.27-1.76 ; p=.0012)$ for class I to $2.61(95 \% \mathrm{Cl} 1.48-4.60 ; p=.0006)$ for class III. Obesity was found to be associated with AHR and appears to be a risk factor for asthma.
\end{abstract}

Key words: airway hyperresponsiveness, asthma, obesity

$R$ ecently, asthma and obesity have evolved into two major health concerns in developed countries. ${ }^{1}$ Over the past 20 years, obesity among adults and children has risen significantly in the United States. The latest data from the National Center for Health Statistics show that 30\% of US adults 20 years of age and older (over 60 million people) and $16 \%$ of children and teens age 6 to 19 years (over 9 million young people) are obese. ${ }^{2}$ In addition, current data overwhelmingly document the existence of a worldwide asthma epidemic, although individual studies remain controversial. ${ }^{3-6}$ The epidemic is thought primarily to involve persons with allergic asthma; numerous diverse theories, based on an immunopathologic understanding of the disease, have recently emerged to explain this involvement. Thus, it appears that during the past three decades, the prevalence of both asthma and obesity has increased concurrently in Western countries, therefore

Sat Sharma and Adarsh Tailor: Section of Respirology, Department of Internal Medicine; Richard Warrington: Section of Allergy and Immunology, Department of Internal Medicine; and Mary Cheang: Department of Community Health Sciences, University of Manitoba, Winnipeg, $M B$.

This study was supported by a grant from Respiratory Research, St. Boniface General Hospital.

Correspondence to: Sat Sharma, MD, FRCPC, Professor and Head, Section of Respirology, University of Manitoba, GF 222, 700 William Avenue, Winnipeg, MB R3E 0Z3; e-mail: ssharma@sbgh.mb.ca.

DOI $10.2310 / 7480.2008 .00008$ suggesting a possible link between the two. ${ }^{7}$ Many publications have shown an association between asthma and obesity in adults and children. ${ }^{7-10}$

Although obesity and asthma remain two of the fastest growing and most pervasive public health problems in developing countries, the question remains whether the relationship of asthma to obesity is a real connection with causal association or rather a misleading observation. Many, but not all, of the studies have shown that the association between obesity and the prevalence of asthma diagnosis is stronger in women than in men. ${ }^{9,10}$ Despite a number of epidemiologic studies supporting an association between asthma and obesity, controversy and inconsistency in the literature remain. The majority of studies support an association, but they are largely observational in design and failed to use objective clinical measures of asthma; therefore, they are susceptible to the diagnostic and recall bias. The few studies that incorporated objective measures did not find an association. ${ }^{10,11}$ Unfortunately, these studies included a relatively small number of patients, and this may have precluded finding an important difference. Additionally, confounding effects of asthma medications used in the obese cohort may have created a bias against an association being found. Although many studies have supported the possible association between obesity and asthma, the scientific literature remains divided regarding the association between airway hyperresponsiveness (AHR) and changes in body mass index (BMI). A recent cross-sectional study of 86,144 
Canadians examined the association between BMI and asthma prevalence. The study found that 1 unit of BMI increase was associated with an approximately $6 \%$ increase in asthma risk in women and a 3\% increase in men. A stronger association between obesity and asthma was observed in non-allergic women than in allergic women. ${ }^{12}$ No definite information on the BMI-adjusted trends in the prevalence of asthma has been published in adults, although data on asthma and BMI were obtained in the National Health and Nutrition Examination Survey (NHANES). ${ }^{13}$

To further investigate the association between obesity and asthma and its possible mechanisms, we investigated the relationship of AHR, a marker of asthma, to obesity in adult subjects. We hypothesized that in a large sample of patients with respiratory symptoms suggestive of asthma referred for confirmation of asthma diagnosis, a positive association exists between BMI and AHR.

\section{Methods}

We evaluated all subjects referred for confirmation of asthma by methacholine challenge test from 1999 to 2004 at the Pulmonary Function Tests Laboratory of St. Boniface General Hospital, Winnipeg. Appropriate Institutional Review Board and hospital approvals were obtained. Based on symptoms, a diagnosis of asthma was suspected by either the primary care physicians or pulmonary specialists. The laboratory database prospectively recorded demographic information, spirometry, and methacholine challenge test data. The chronicled demographic information included age, sex, race, height, weight, referring physician's diagnosis, smoking history, medications, and history of cardiac disease. Evaluation of all subjects and spirometric testing was done by experienced pulmonary technologists certified and licensed by the Canadian College of Respiratory Therapists and the Canadian Association of Cardio-Pulmonary Technologists. In addition, the technologists validated the information provided by the referring physician and documented asthma history as part of the previously established standard laboratory protocol. To minimize confounding by other conditions in which (AHR) has been reported (chronic obstructive pulmonary disease [COPD], sarcoidosis, bronchiectasis, and cardiac disease and $\beta$-blocking medications), we excluded these subjects. Additionally, subjects with a history of smoking ( $\geq 10$ pack-years), chronic steroid use, and suspected restrictive pulmonary disease (forced vital capacity $[\mathrm{FVC}]<80 \%$ predicted and ratio of forced expiratory volume in 1 second $\left[\mathrm{FEV}_{1}\right]$ to FVC $\geq 80 \%$ ) were excluded from the study.

Spirometry was performed according to American Thoracic Society criteria. ${ }^{14}$ Testing was done with the subjects seated, and a maximum forced exhalation was carried out for a minimum of 6 seconds. After 6 seconds, the test continued until zero flow was achieved $(\leq 50 \mathrm{~mL}$ flow extrapolated over 30 seconds). At least three FVC manoeuvres were performed, two of which were reproducible within $5 \%$. Spirometric measurements were made using the PFT Horizon System SensorMedics Corp. (Yorba Linda, CA, USA); the machines were calibrated daily with a $3 \mathrm{~L}$ volumetric syringe. All $\beta_{2}$-agonist medications were withheld at least 6 hours before testing. The methacholine challenge test was performed in a standard fashion. ${ }^{15} \mathrm{FVC}$ and $\mathrm{FEV}_{1}$ were measured after inhalation of normal saline and after doubling concentrations of methacholine from 0.03 to $16.0 \mathrm{mg} / \mathrm{mL}$ in normal saline solution. The methacholine solution was delivered using a Wright twin nebulizer and inhaled by tidal breathing for 2 minutes with the nose clipped. FVC and $\mathrm{FEV}_{1}$ were measured at 30 and 90 seconds after each dose. Doubling concentrations of methacholine were administered at 5-minute intervals until the $\mathrm{FEV}_{1}$ decreased by $20 \%$ from the lowest value following saline solution $\mathrm{FEV}_{1}$ or until a dose of $16 \mathrm{mg} / \mathrm{mL}$ was achieved. The provocative concentration of methacholine causing a $20 \%$ fall in $\mathrm{FEV}_{1}\left(\mathrm{PC}_{20}\right)$ was calculated by linear interpolation of the last two points. The subjects with a fall in $\mathrm{FEV}_{1}$ of $20 \%$ or more with less than $8 \mathrm{mg} / \mathrm{mL}$ methacholine were defined as having AHR.

Obesity was defined as $[$ BMI $=$ weight $(\mathrm{kg}) /$ height $(\mathrm{m})$ squared $\left.(\mathrm{ht} \times \mathrm{ht}) \geq 30 \mathrm{~kg} / \mathrm{m}^{2}\right]$. Non-obese individuals were defined as BMI $<30 \mathrm{~kg} / \mathrm{m}^{2}$. Obese individuals were further classified as obesity class I, BMI from 30.0 to 34.9 ; obesity class II, BMI from 35 to 39.9; and obesity class III for $\mathrm{BMI} \geq 40.0$.

\section{Statistical Analysis}

Continuous variables were expressed as mean \pm SD. Prevalence rates and mean values are reported with 95\% confidence intervals. The $\chi 2$ test was used to determine the significance of differences in prevalence across all BMI groups and between different BMI groups, determined by increasing cutoff values compared with their control groups. Odds ratios (ORs), relative risks (RRs), and attributable risks (ARs) $(\mathrm{AR}=$ risk ratio -1 /risk ratio) were estimated for AHR in the presence of obesity. Correlates of BMI and AHR were studied with analysis of variance (ANOVA) or Wilcoxon rank sum tests where 
applicable. For all analyses, $p$ values of $<.05$ were regarded as significant. The Cochran-Mantel-Haenszel test was also used to stratify the results by gender. Pearson correlation coefficient was used to assess the association between continuous BMI and airway responsiveness. Two-way ANOVA was used to analyze means of grouped data, and least-square means post hoc analysis using the pooled variance was also performed to correct for multiple comparisons when comparing specific groups. The Mantel-Haenszel trend test was performed as the data suggested that there might be a dose-response trend. Microsoft Excel and SAS version 9.1 (SAS Inc, Cary, NC) were used for the data analysis.

\section{Results}

The analysis included 861 subjects: 337 (39\%) were obese and 401 (47\%) demonstrated AHR (Table 1). The mean methacholine dose $\left(\mathrm{PC}_{20}\right)$ was $4.16 \pm 2.55 \mathrm{mg} / \mathrm{mL}$. Spirometric measurements of $\mathrm{FVC}, \mathrm{FEV}_{1}$, and ratio of $\mathrm{FEV}_{1}$ to $\mathrm{FVC}$ in methacholine-positive versus -negative subjects were not statistically different. The mean FVC $(89.67 \pm 14.88$ vs $92.14 \pm 15.40)$, mean $\mathrm{FEV}_{1}(98.93 \pm$ 15.34 vs $98.40 \pm 16.17$ ), and mean ratio of $\mathrm{FEV}_{1}$ to $\mathrm{FVC}$ $(85 \pm 9.3$ vs $81 \pm 9.5)$ were measured within the two groups. There was a significant association between obesity and AHR for all subjects; the OR was 1.37 (95\% CI 1.02$1.82 ; p=.0317)$. When used as a continuous variable in logistic regression models, one unit of increased BMI

Table 1. Demographics of Total Evaluated and Included Patients

\begin{tabular}{lc}
\hline Characteristics & Number (\%) \\
\hline Number of subjects evaluated & 1,372 \\
Number of subjects included & $861(63 \%)$ \\
Number of subjects excluded & 511 \\
Reasons of exclusion & \\
COPD & 293 \\
Smoking history ( $>10$ pk-yr) & 168 \\
Restrictive lung disease & 38 \\
Congestive heart failure & 12 \\
Number of subjects with bronchial & $401(47 \%)$ \\
hyperresponsiveness & 337 \\
Number with obesity $>30 \mathrm{~kg} / \mathrm{m}^{2}$ & $89.67 \pm 14.88$ \\
Mean FVC (\% predicted) in & \\
subjects with AHR & $98.93 \pm 15.34$ \\
Mean FEV & (\% predicted) in \\
subjects with AHR & \\
\hline
\end{tabular}

$\mathrm{AHR}=$ airway hyperresponsiveness; $\mathrm{COPD}=$ chronic obstructive pulmonary disease; $\mathrm{FEV}_{1}=$ forced expiratory volume in 1 second; FVC $=$ forced vital capacity. $\left(1 \mathrm{~kg} / \mathrm{m}^{2}\right)$ was associated with a $3.1 \%$ increase in AHR risk (CI 1.01-1.05; $p<.005)$ in all subjects. For men, this risk was 3.4\% (CI 1.01-1.06) for one unit of increased BMI $\left(1 \mathrm{~kg} / \mathrm{m}^{2}\right)$ and for women $2 \%$ (CI $\left.0.97-1.07\right)$, respectively.

The OR for point estimates of AHR risk in obesity was 1.09 (CI 0.76-1.54) for class I, 1.5 (CI 0.92-2.46) for class II, and 2.78 (CI 1.56-4.94) for class III (Table 2). The $p$ values were .64 for class I, .10 for class II, and .0005 for class III. When different thresholds for obesity were used as cutoffs, the association became increasingly significant as the level of obesity increased from class I to class III. ORs for class I obesity were 1.86 (95\% CI 1.27-1.76; $p=.0012)$ and for obesity class III were $2.61(95 \%$ CI $1.48-4.60 ; p=.0006$ ) (Table 3). Likewise, the RR increased from 1.22 to 1.67 to 1.86 for obesity class I to class II and class III, respectively. The attributable risk for the entire group increased from 17.83 to 30.43 to $40.13 \%$ for obesity classes I, II, and III, respectively. Using multiple regression, for the positive methacholine challenge test, the ageadjusted OR for BMI $\geq 30$ was 1.44 (95\% CI 1.07-1.93; $p=.014)$, for $\mathrm{BMI} \geq 35$ was 1.93 (95\% CI 1.32-2.84; $p=$ .007 ), and for BMI $\geq 40$ was 2.71 (95\% CI 1.54-4.79; $p=$ .0006). The age-adjusted OR for the positive methacholine challenge for a $1 \mathrm{~kg} / \mathrm{m}^{2}$ change in BMI was 1.037 (95\% CI 1.01-1.06).

On stratifying data according to sex difference, we found dissimilar results. For males, obesity class I did not appear to be a significant risk factor. However, for higher levels of obesity, classes II and III, there was a positive association between obesity and AHR. The OR was 2.75 (95\% CI 1.21-6.20) and the AR was $41 \%$ for class II obesity in men, whereas the OR was 4.82 and the AR was $51 \%$ for males with class II obesity. In females, obesity was a significant risk factor for AHR at all levels of obesity. Class I obesity had an OR of 1.47 (95\% CI 1.04-2.08) and an $\mathrm{AR}$ of $22 \%$, whereas a higher risk was observed with obesity classes II and III, in which the ORs and ARs were 1.72 (95\% CI $1.11-2.65)$ and $28 \%$ and 2.4 (95\% CI $1.26-4.55)$ and $38 \%$, respectively.

Table 2. Point Estimates of Airway Hyperresponsiveness in All Patients When Grouped as BMI 30 to 34.9, BMI 35 to 39.9, and $\mathrm{BMI} \geq 40$ Compared with BMI $<30$

\begin{tabular}{lccc}
\hline BMI & Odds Ratio & $95 \%$ CI & p Value \\
\hline $30-34.9$ & 1.09 & $0.76-1.54$ & .64 \\
$35-39.9$ & 1.50 & $0.92-2.46$ & .10 \\
$\geq 40$ & 2.78 & $1.56-4.94$ & .0005 \\
\hline
\end{tabular}

$\mathrm{BMI}=$ body mass index $\mathrm{CI}=$ confidence interval. 
Table 3. Relationship to Airway Hyperresponsiveness in All Patients Using a Cutoff Value for Body Mass Index at 30, 35, and 40

\begin{tabular}{|c|c|c|c|c|c|c|c|}
\hline BMI & Age (yr) & $\begin{array}{c}\% \text { Methacholine } \\
\text { Positive }\end{array}$ & Odds Ratio & $\begin{array}{c}95 \% \text { CI for Odds } \\
\text { Ratio }\end{array}$ & Relative Risk (CI) & $\begin{array}{c}\text { Attributable } \\
\text { Risk (\%) }\end{array}$ & $\mathrm{p}$ Value \\
\hline$<30$ & $44.5 \pm 16.4$ & 33.82 & 1.37 & $1.03-1.82$ & $1.22(1.02-1.45)$ & 17.83 & .0317 \\
\hline$\geq 30$ & $49.1 \pm 14.2$ & 41.16 & & & & & \\
\hline$<35$ & $45.7 \pm 16.1$ & 34.24 & 1.86 & $1.27-1.76$ & $1.67(1.17-1.76)$ & 30.43 & .0012 \\
\hline$\geq 35$ & $49.1 \pm 13.4$ & 49.22 & & & & & \\
\hline$<40$ & $46 \pm 16$ & 35.02 & 2.61 & $1.48-4.60$ & $1.86(1.31-2.13)$ & 40.13 & .0006 \\
\hline$\geq 40$ & $49.5 \pm 11.3$ & 58.49 & & & & & \\
\hline
\end{tabular}

$\mathrm{BMI}=$ body mass index; $\mathrm{CI}=$ confidence interval.

\section{Discussion}

We found obesity to be a significant risk factor for AHR in subjects suspected of having asthma. According to the Canadian Asthma Consensus Guidelines, asthma is defined as "a disease characterized by paroxysmal or persistent symptoms of dyspnea, chest tightness, wheezing, sputum production, and cough associated with variable airflow limitation and airway responsiveness to exogenous stimuli." ${ }^{\prime 16}$ For epidemiologic purposes, asthma is defined as current symptoms of dyspnea and/or wheeze within the last 12 months, together with documented AHR. ${ }^{17}$ The $\mathrm{PC}_{20}$ is usually interpreted in the context of pretest and posttest probability of asthma. ${ }^{18,19}$ The subjects in this study were referred for confirmation of asthma diagnosis because of respiratory symptoms, thus carrying a high pretest probability of asthma. Therefore, following a positive methacholine challenge test $\left(\right.$ mean $\mathrm{PC}_{20}$ dose $=4.16 \pm 2.55 \mathrm{mg} / \mathrm{mL}$ ), a high posttest probability of asthma in these subjects exists. AHR has also been reported in patients with COPD. ${ }^{20}$ However, we excluded individuals with COPD based on spirometry and smoking history. When analyzing data for sex differences, similar to other published studies, we found obesity to be a significant risk factor for AHR at all levels of obesity for females but only for higher levels of obesity for men. ${ }^{11,21,22}$

\section{Literature Review}

Previous observational studies support an association between AHR and asthma and obesity. Based on Canadian National Population Health Survey data from 1994-1995, Chen and colleagues found that BMI values were positively associated with prevalence of asthma in women. ${ }^{8}$ The adjusted OR was 1.52 for women with a BMI of $28.0 \mathrm{~kg} / \mathrm{m}^{2}$ or more compared with those with a BMI of 20.0 to $24.9 \mathrm{~kg} / \mathrm{m}^{2}$. Shaheen and colleagues found that the

Table 4. Sex Differences for Airway Hyperresponsiveness Prevalence with Body Mass Index

\begin{tabular}{|c|c|c|c|c|c|c|c|c|c|c|c|c|}
\hline \multirow{3}{*}{$\frac{\text { Patient Attribute }}{\text { BMI }}$} & \multicolumn{4}{|c|}{$\begin{array}{c}\text { Prevalence of } A H R \text { in Subjects } \\
\text { with } B M I<30 \text { or } \geq 30\end{array}$} & \multicolumn{4}{|c|}{$\begin{array}{c}\text { Prevalence of AHR in Subjects } \\
\text { with } B M I<35 \text { or } \geq 35\end{array}$} & \multicolumn{4}{|c|}{$\begin{array}{l}\text { Prevalence of AHR in Subjects with } \\
\qquad B M I<40 \text { or } \geq 40\end{array}$} \\
\hline & \multicolumn{2}{|c|}{ Female } & \multicolumn{2}{|c|}{ Male } & \multicolumn{2}{|c|}{ Female } & \multicolumn{2}{|c|}{ Male } & \multicolumn{2}{|c|}{ Female } & \multicolumn{2}{|c|}{ Male } \\
\hline & $<30$ & $\geq 30$ & $<30$ & $\geq 30$ & $<35$ & $\geq 35$ & $<35$ & $\geq 35$ & $<40$ & $\geq 40$ & $<40$ & $\geq 40$ \\
\hline $\begin{array}{l}\text { Total number of } \\
\text { subjects }\end{array}$ & 382 & 230 & 153 & 96 & 496 & 100 & 234 & 31 & 555 & 41 & 250 & 15 \\
\hline $\begin{array}{l}\% \text { Methacholine } \\
\text { positive }\end{array}$ & 33 & 42 & 36 & 39 & 34 & 47 & 35 & 59 & 35 & 56 & 35 & 73 \\
\hline Odds ratio $(\mathrm{CI})$ & \multicolumn{2}{|c|}{$1.47(1.04-2.08)$} & \multicolumn{2}{|c|}{$1.17(0.70-1.98)$} & \multicolumn{2}{|c|}{$1.72(1.11-2.65)$} & \multicolumn{2}{|c|}{$2.75(1.21-6.20)$} & \multicolumn{2}{|c|}{$2.40(1.26-4.55)$} & \multicolumn{2}{|c|}{$4.82(1.25-18.6)$} \\
\hline$p$ Value & \multicolumn{2}{|c|}{.03} & \multicolumn{2}{|c|}{.54} & \multicolumn{2}{|c|}{.01} & \multicolumn{2}{|c|}{.01} & \multicolumn{2}{|c|}{.006} & \multicolumn{2}{|c|}{.01} \\
\hline Relative risk & \multicolumn{2}{|c|}{1.27} & \multicolumn{2}{|c|}{1.12} & \multicolumn{2}{|c|}{1.38} & \multicolumn{2}{|c|}{1.71} & \multicolumn{2}{|c|}{1.61} & \multicolumn{2}{|c|}{2.04} \\
\hline $\begin{array}{l}\text { Attributable risk } \\
(\%)\end{array}$ & \multicolumn{2}{|c|}{22} & \multicolumn{2}{|c|}{10} & \multicolumn{2}{|c|}{28} & \multicolumn{2}{|c|}{41} & \multicolumn{2}{|c|}{38} & \multicolumn{2}{|c|}{51} \\
\hline
\end{tabular}

$\mathrm{AHR}=$ airway hyperresponsiveness; $\mathrm{BMI}=$ body mass index; $\mathrm{CI}=$ confidence interval. 
ORs for the prevalence of asthma among 8,960 British adults were higher in overweight women. ${ }^{9}$ ORs were 1.51 in those with a BMI of 25.0 to $29.9 \mathrm{~kg} / \mathrm{m}^{2}$ and 1.84 in those with a BMI of at least $30.0 \mathrm{~kg} / \mathrm{m}^{2}$ compared with those with a BMI less than $25.0 \mathrm{~kg} / \mathrm{m}^{2}$. Luder and colleagues reported similar associations between BMI and physiciandiagnosed asthma based on data from 5,527 adults living in New York State. ${ }^{10}$ Several longitudinal epidemiologic studies have yielded similar results. ${ }^{8-12}$ Findings from the Nurses' Health Study suggest that a $25 \mathrm{~kg}$ weight gain was associated with a 2.5 -fold increase in the risk for diagnosis of asthma compared with no significant weight gain. ${ }^{11}$ In a cross-sectional analysis of 18,000 children aged 4 to 11 years, Figueroa-Munoz and colleagues showed that asthma diagnosis and BMI were positively associated $(\mathrm{OR}=1.29$, 95\% CI 1.13-1.47). ${ }^{21}$ Gilliland and colleagues showed that the risk of new-onset asthma was higher among obese children ( $\mathrm{RR}=1.60,95 \% \mathrm{CI} 1.08-2.36)$ and found this effect to be stronger in boys. ${ }^{22}$

Other investigators did not find such an association and thus speculated that asthma might be overdiagnosed in obese subjects. Schachter and colleagues studied 1,971 Australian adults in a cross-sectional epidemiologic study and found that obesity was a significant risk factor for diagnosis of asthma ( $\mathrm{OR}=$ $2.04)$, wheeze, and asthma medication use $(\mathrm{OR}=2.83)$ but not for AHR, atopy, or airflow obstruction. ${ }^{23}$ Despite more symptoms consistent with asthma and use of more asthma medications in severely obese subjects, the level of AHR and airflow obstruction did not support higher prevalence of asthma. Sin and colleagues examined data from NHANES III and showed that the most obese participants $\left(\right.$ BMI $>31 \mathrm{~kg} / \mathrm{m}^{2}$ ) had the greatest risk of self-reported asthma, dyspnea, and bronchodilator use but paradoxically were found to have lower risk for airflow obstruction. ${ }^{13}$ Obese subjects used more bronchodilators than non-obese subjects without objective evidence of airflow obstruction, and asthma was overdiagnosed in this obese population. In a cross-sectional study of 86,144 Canadians who were 20 to 64 years of age, a stronger association between obesity and asthma was observed in non-allergic women than in allergic women, with the adjusted ORs being 2.53 (95\% CI 2.11-3.04) and 1.57 (95\% CI 1.36-1.82), respectively. ${ }^{12}$

\section{Biological Plausibility}

To establish causality between obesity, asthma, and BHR, plausible biological mechanisms must be proved to support this hypothesis. Obesity may directly affect individuals with asthma predisposition by direct mechanical effects, by immune response enhancement through related genetic mechanisms, and by sex-specific hormones. ${ }^{24}$ Since obesity is intricately linked to environmental factors such as physical activity, diet, and birth weight, these environmental influences, in combination with genetic predilection, may then lead to enhanced susceptibility to asthma. Undoubtedly, obesity is known to produce symptoms of dyspnea and wheezing; whether asthma and airflow obstruction are responsible for these symptoms has not been conclusively ascertained. The reduced chest wall compliance in obesity causes a substantial elastic load on inspiratory muscles and increases the work and the energy costs of breathing. ${ }^{25,26}$ Obesity induces a reduction in functional residual capacity (FRC) and decrements in tidal volume, which fail to increase during exercise. ${ }^{27}$ Thus, waning FRC and tidal volumes may result in alterations in the airway smooth muscles and hence increased airways resistance and methacholine reactivity. Therefore, obese patients complain of more dyspnea and asthma-like symptoms than leaner patients and may be incorrectly diagnosed with asthma. ${ }^{28,29}$ In addition, obesity has been associated with decrements in forced expiratory flow (FEF) in the midportion of FVC $\left(\mathrm{FEF}_{25-75}\right)$. The ratio of $\mathrm{FEF}_{25-75}$ to FVC has also been independently associated with methacholine responsiveness of the airways. ${ }^{30}$ Gastroesophageal reflux (GER) is commonly seen in patients with asthma; the prevalence of GER is estimated to be 60 to $80 \%{ }^{31}$ Since obesity has been frequently cited as an independent risk factor for GER, one may speculate that GER might mediate the relationship between asthma and obesity.

Asthma and obesity are both inflammatory states. ${ }^{16}$ Allergic asthma is characterized by elevation of the cytokines interleukin (IL)-4 and IL-5, which are responsible for the inflammatory cells infiltrating the airways. ${ }^{32}$ Tumour necrosis factor $\alpha$ (TNF- $\alpha$ ), IL-1 $\beta$, and IL- 6 are also increased in asthmatics. Obesity is also a chronic inflammatory state. ${ }^{33}$ Fat cells (adipocytes) are an important endocrine organ that produces a number of compounds that regulate inflammation such as IL- $1 \beta$, IL-6, TNF- $\alpha$, leptin, and adiponectin. ${ }^{34}$ Animal studies indicate that elevations in IL-6 may contribute to upregulation of inflammation in airways, independent of an allergic mechanism. IL-6 increases production of prostaglandin $\mathrm{E}_{2}\left(\mathrm{PGE}_{2}\right)$, stimulating the humoral immune system and production of T-helper 2 (Th2)associated cytokines. ${ }^{35} \mathrm{PGE}_{2}$ does this by modulating 
professional dendritic cells, by acting on their differentiation, maturation, and ability to secrete cytokines. ${ }^{36} \mathrm{PGE}_{2}$ is a potent inducer of IL-10 in bone marrow-derived dendritic cells, and this cytokine displays both immunostimulatory and immunoregulatory activities. ${ }^{37} \mathrm{PGE}_{2}$ can also act on immature dendritic cells to trigger local Th2 recruitment via control of cytokine production. ${ }^{38}$ The hormone leptin of the IL-6 family has effects on inflammation, including the release of IL-6 from macrophages and lymphocytes. ${ }^{39,40}$ Leptin levels in adulthood are higher in women than in men, along with a higher prevalence of asthma. ${ }^{41}$ But the specific role of leptin and the recently described adipocytokines, such as adiponectin, resistin, and visfatin, remains undefined. ${ }^{42}$

Interestingly, in most but not all studies, BMI has not been independently related to atopy, so the effects of obesity, other than immune mechanisms, are mediated through hormonal influences. The study by Huang and colleagues showed that girls in the highest BMI quintile had a significantly higher prevalence of atopy and rhinitis symptoms than girls in the lowest BMI quintile. ${ }^{43}$ In contrast, Jang and colleagues and Jarvis and colleagues found no association between BMI and atopy. ${ }^{44,45}$ In a study of children with a mean age of 5.9 years, Guler and colleagues found that atopic asthmatics had significantly higher leptin levels for a similar BMI than non-atopic asthmatics, but this did not correlate with skin test reactivity. ${ }^{46}$ An explanation for these disparities may come from the study of Vieira and colleagues, who found that in healthy obese and non-obese women, specific immunoglobulin E (IgE) was three times higher in obese compared with non-obese subjects, as were plasma $17 \beta$-estradiol, fasting insulin resistance, C-peptide, and leptin concentrations. ${ }^{47}$ All of these factors correlated with fat mass, which was the only positive predictor of specific IgE. Thus, female sex hormones may also play a role, given the increased risk of asthma development in women. ${ }^{48}$ The effect of female hormone levels may also be related to our findings of significant BHR in obesity class I compared with men. Obesity may reduce progesterone, which would reduce $\beta_{2}$-receptor function, which may reduce bronchial smooth muscle relaxation and worsen asthma control. Weight loss increases progesterone and adrenoreceptor density and improves lung function in obese females with asthma. Although some effect of estrogen levels on airways responsiveness is seen in animal modes, it is not clear which airway cells express estrogen receptors and/or if signalling pathways via estrogen receptors interact with airway inflammation in asthma. $^{49,50}$

\section{Implications of Obesity and Asthma Causality}

Our and other epidemiologic investigations denote a significant temporal relationship between alterations in body mass and asthma. This association is probably multifactorial; however, the potential independent effects of biomechanics, inflammation, genetics, and sex-specific effects contradict this association. Research is urgently needed to further elucidate this relationship and understand the causal mechanisms of obesity and asthma association. From a public health standpoint, these studies have substantial implications. If asthma were added to the list of conditions related to obesity, then reducing the prevalence of obesity could be expected to produce even greater public health benefits than are currently estimated. It may be too early to incorporate weight reduction strategies in efforts to reduce the health and economic burden of asthma; however, current evidence mandates that such interventions should not be delayed either.

\section{Limitations of Our Study}

Ours is an observational cohort study that includes inherent limitations, such as the lack of an age- and sexmatched control group, its retrospective nature, relatively small sample size, and inability to categorize clinical asthma severity. All patients included in this study were referred to a tertiary care centre for evaluation of respiratory symptoms, therefore creating a selection bias. Despite these limitations, our study attained some important observations, which can have potential implications in designing future health policies.

\section{Conclusion}

In summary, obesity and asthma are the two fastest growing health problems worldwide; there appears to be a genuine association between the two. Our study established obesity as a risk factor for new diagnosis of asthma, the risk increasing with higher levels of obesity. These findings should be the basis for future controlled investigations to further establish this association and discover the biological mechanisms for their association.

\section{References}

1. Elamin EM. Asthma and obesity: a real connection or a casual association? Chest 2004;125:1972-4.

2. State-specific prevalence of obesity among adults-United States. MMWR Morb Mortal Wkly Rep 2006;55:985-8. 
3. Mannino DM, Homa DM, Pertowski CA, et al. Surveillance for asthma-United States, 1960-1995. MMWR CDC Surveill Summ 1998;47:1-27.

4. Weiss KB, Gergen PJ, Hodgson TA. Economic evaluation of asthma in the United States. N Engl J Med 1992;326:862-6.

5. Weiss KB, Sullivan SD. The health economics of asthma and rhinitis-assessing the economic impact. J Allergy Clin Immunol 2001;107:3-8.

6. Grant EN, Wagner R, Weiss KB. Observations on emerging patterns of asthma in our society. J Allergy Clin Immunol 1999;104 (2 Pt 2):S1-9.

7. Chinn S. Obesity and asthma. Paeditr Respir Rev 2006;7:223-8.

8. Chen Y, Dales R, Tang M, et al. Obesity in women but not in men may increase the incidence of asthma: longitudinal observations from the Canadian National Population Health Surveys. Am J Epidemiol 2002;155:1-7.

9. Shaheen SO, Sterne JAC, Montgomery SM, et al. Birth weight, body mass index and asthma in young adults. Thorax 1999;54:396402.

10. Luder E, Melnik TA, DiMaio M. Association of being overweight with greater asthma symptoms in inner city black and Hispanic children. J Pediatr 1998;132:699-703.

11. Camargo CA Jr, Weiss ST, Zhang S, et al. Prospective study of body mass index, weight change, and risk of adult-onset asthma in women. Arch Intern Med 1999;159:2582-8.

12. Chen Y, Dales R, Jiang Y. The association between obesity nonallergic than allergic adults. Chest 2006;130:890-5.

13. Sin DD, Jones RL, Man SF. Obesity is a risk factor for dyspnea but not for airflow obstruction. Arch Intern Med 2002;162:1477-81.

14. Standardization of spirometry. American Thoracic Society statement. Am J Respir Crit Care Med 1994;152:1107-37.

15. American Thoracic Society. Guidelines for methacholine and exercise challenge testing. Am J Respir Crit Care Med 2000;161: 309-29.

16. Lemiere $\mathrm{C}$, and the Canadian Adult Consensus Group of the Canadian Thoracic Society. Adult asthma consensus guidelines update 2003. Can Respir J 2004;11 Suppl A:9a-10a.

17. Toelle BG, Peat JK, Salome CM, et al. Toward a definition of asthma for epidemiology. Am Rev Respir Dis 1992;146:633-67.

18. Boushey HA, Holtzman MJ, Sheller JR, et al. Bronchial hyperreactivity. Am Rev Respir Dis 1980;121:389-413.

19. Dehaut P, Rachiele A, Martin RR, et al. Histamine dose-response curves in asthma: reproducibility and sensitivity of different indices to assess response. Thorax 1983;38:516-22.

20. Tashkin DP, Altose MD, Connett JE, et al. Methacholine reactivity predicts changes in lung function over time in smokers with early chronic obstructive pulmonary disease. The Lung Health Study Research Group. Am J Respir Crit Care Med 1996;153:180211.

21. Figueroa-Munoz JI, Chinn S, Rona RJ. Association between obesity and asthma in 4-11-year-old children in the UK. Thorax 2001;56: 133-7.

22. Gilliland FD, Berhane K, Islam T, et al. Obesity and the risk of newly diagnosed asthma in school-age children. Am J Epidemiol 2003;158:406-15.

23. Schachter LM, Salome CM, Peat JK, et al. Obesity is a risk for asthma and wheeze but not airway hyperresponsiveness. Thorax 2001;56:4-8.
24. Naimark A, Cherniack RM. Compliance of the respiratory system and its components in health and obesity. J Appl Physiol 1960;15: 377-82.

25. Beuther DA, Weiss ST, Sutherland ER. Obesity and asthma. Am J Respir Crit Care Med 2006;174:112-9.

26. Sharp JT, Barrocas M, Chokroverty S. The cardiorespiratory effects of obesity. Clin Chest Med 1980;1:103-18.

27. Inselma LS, Milanese A, Deurloo A. Effect of obesity on pulmonary function in children. Pediatr Pulmonol 1993;16:130-7.

28. Sharp JT, Henry JP, Sweany SK, et al. The total work of breathing in normal and obese men. J Clin Invest 1964;43:72839.

29. Hakala K, Stenius-Aarniala B, Sovijarvi A. Effects of weight loss on peak flow variability, airways obstruction, and lung volumes in obese patients with asthma. Chest 2000;118:1315-21.

30. Litonjua AA, Sparrow D, Weiss ST. The FEF25-75/FVC ratio is associated with methacholine airway responsiveness. The Normative Aging Study. Am J Respir Crit Care Med 1999;159: 1574-9.

31. Sontag SJ. Gastroesophageal reflux disease and asthma. J Clin Gastroenterol 2000;30(Suppl):S9-30.

32. Drazen JM, Arm JP, Austen KF. Sorting out the cytokines of asthma. J Exp Med 1996;183:1-5.

33. Mukhopadhyay S, Hoidal JR, Mukherjee TK. Role of TNF alpha in pulmonary pathophysiology. Respir Res 2006;7:125.

34. Wisse BE. The inflammatory syndrome: the role of adipose tissue cytokines in metabolic disorders linked to obesity. J Am Soc Nephrol 2004;15:2792-800.

35. Varner AE. An immunologic mechanism for the association between obesity and asthma. Arch Intern Med 2000;160: 2395-6.

36. Harizi H, Gualde N. Pivotal role of PGE2 and IL-10 in the crossregulation of dendritic cell-derived inflammatory mediators. Cell Mol Immunol 2004;82:353-60.

37. Gualde N, Harizi H. Prostanoids and their receptors that modulate dendritic cell-mediated immunity. Immunol Cell Biol 2004;82: 353-60.

38. McIroy A, Caron G, Blanchard S, et al. Histamine and prostaglandin $\mathrm{E}$ up-regulate the production of $\mathrm{TH}-2$ attracting chemokines (CCL17 and CCL22) and down-regulate IFN-gammainduced CXCL10 production by immature human dendritic cells. Immunology 2006;117:507-16.

39. Rosenbaum M, Nicolson M, Hirsch J, et al. Effects of gender, body composition, and menopause on plasma concentrations of leptin. J Clin Endocrinol Metab 1996;81:3424-7.

40. Tantisira KG, Weiss ST. Complex interactions in complex traits: obesity and asthma. Thorax 2001;56 Suppl 2:ii64-74.

41. Maffei M, Halaas J, Ravussin E, et al. Leptin levels in human and rodent: measurement of plasma leptin and ob RNA in obese and weight-reduced subjects. Nat Med 1995;1:1155-61.

42. Tilg H, Moschen AR. Adipocytokines: mediators linking adipose tissue, inflammation and immunity. Nat Rev Immunol 2006;6: 772-83.

43. Huang SL, Shiao G, Chou P. Association between body mass index and allergy in teenage girls in Taiwan. Clin Exp Allergy 1999;29: 323-9.

44. Jang A-S, Son M-H, Choi I-S, et al. High body mass index is associated with wheezing among older adults living in high altitude area in Korea. J Korean Med Sci 2002;17:479-82. 
45. Jarvis D, Chinn S, Potts J, et al. Association of body mass index with respiratory symptoms and atopy: results from the European Community Respiratory Health Survey. Clin Exp Allergy 2002;32: $831-7$.

46. Guler N, Kirerleri E, Ones U, et al. Leptin: does it have any role in childhood asthma? J Allergy Clin Immunol 2004;114:2549.

47. Vieira VJ, Ronan AM, Windt MR, et al. Elevated atopy in healthy obese women. Am J Clin Nutr 2005;82:504-9.
48. Cooper C, Kuh D, Egger P, et al. Childhood growth and age at menarche. Br J Obstet Gynaecol 1996;103:814-7.

49. Degano B, Mourlanette P, Valmary S, et al. Differential effects of low and high-dose estradiol on airway reactivity in ovariectomized rats. Respir Physiol Neurobiol 2003;138:265-74.

50. Degano B, Prevost MC, Berger P, et al. Estradiol decreases the acetylcholine-elicited airway reactivity in ovariectomized rats through an increase in epithelial acetylcholinesterase activity. Am J Respir Crit Care Med 2001;164:1849-54. 